\title{
Gianluigi Goggi, Diderot e il paradigma repubblicano: il ricorso all'eloquenza politica
}

\section{Gianmaria Zamagni}

\section{(2) OpenEdition}

1 Journals

\section{Edizione digitale}

URL: https://journals.openedition.org/studifrancesi/40792

DOI: 10.4000/studifrancesi.40792

ISSN: 2421-5856

\section{Editore}

Rosenberg \& Sellier

\section{Edizione cartacea}

Data di pubblicazione: 1 juillet 2004

Paginazione: 199

ISSN: 0039-2944

\section{Notizia bibliografica digitale}

Gianmaria Zamagni, «Gianluigi Goggi, Diderot e il paradigma repubblicano: il ricorso all'eloquenza politica», Studi Francesi [Online], 142 (XLVIII | I) | 2004, online dal 30 novembre 2015, consultato il 09 septembre 2021. URL: http://journals.openedition.org/studifrancesi/40792 ; DOI: https://doi.org/ 10.4000/studifrancesi.40792

Questo documento è stato generato automaticamente il 9 septembre 2021.

\section{(c)}

Studi Francesi è distribuita con Licenza Creative Commons Attribuzione - Non commerciale - Non opere derivate 4.0 Internazionale. 


\title{
Gianluigi Goggi, Diderot e il paradigma repubblicano: il ricorso all'eloquenza politica
}

\author{
Gianmaria Zamagni
}

\section{NOTIZIA}

GIANLUIGI GOGGI, Diderot e il paradigma repubblicano: il ricorso all'eloquenza politica, in Ideali repubblicani in età moderna, a cura di Fiorella DE MICHELIS PINTACUDA e Gianni FRANCIONI, Pisa, ETS, 2002, pp. 283-318.

1 Il saggio di Gianluigi Goggi prende lo spunto dalla distinzione teoretica operata da John G.A. Pocok ira i paradigmi classico-repubblicano e moderno-giusnaturalistico, per giudicare se Diderot resti all'intemo del secondo modello, improntato ai valori del commercio e dell'utile, al volgere degli anni '70 del Settecento. È in questa fase infatti che il philosophe, collaborando profondamente alla terza edizione dell'opera dell'abbé Raynal Histoire des deux Indes, sembra sfuggire a quel paradigma nella direzione di una rivalutazione dell'eloquenza, tipica della costellazione repubblicana. Come mostra Goggi, la collaborazione di Diderot consiste soprattutto nell'inserzione di «morceaux éloquents» all'intemo di quella storia del commercio, che peraltro la rendono un'opera farraginosa ed eteroclita poiché mirano a dominare in schemi generali lo «stoccaggio dei dati in una griglia», e fanno oscillare l'Histoire tra i moderni principi del calcolo e del commercio (ovvero delle relazioni tra cose) e i principi di una storiografia classica, fatta dell'appello alla virtù (ossia delle relazioni tra persone).

2 Il contributo dell'autore consiste proprio nel mostrare quanto queste inserzioni siano dovute alla collaborazione con Diderot, quest'ultimo mosso anzitutto dal mutato gusto del pubblico, ma non solo. Goggi sostiene infatti che «la storia eloquente si configuri, alla svolta degli anni ' 70 , come il canale di comunicazione, come il medium più adatto a portare avanti la battaglia delle Lumières» (p. 299). Questa battaglia deve venir intesa 
nel senso di una contrapposizione a Hobbes e al suo De cive, poiché la ripresa da quest'opera dell'immagine di Medea (che per ringiovanire il proprio padre lo fa a pezzi) viene ora intesa in senso positivo: 1'eloquenza può in questo caso "riformare» (in maniera rivoluzionaria) uno Stato decaduto e corrotto. Il Diderot di questi anni è un ammiratore entusiasta non solo dei contemporanei movimenti di protesta inglesi (Wilkes and liberty, 1768-69), di cui loda la capacità di «réveiller dans les âmes le démon patriotique» attraverso l'eloquenza (cit. p. 305), ma nondimeno della lotta delle colonie americane per l'indipendenza (J. Dickinson), testimone anch'essa dell'importanza dell'arte di governare gli uomini con le parole, o quantomeno d'«inspirer un amour violent de la liberté» (cit. p. 309). Questi due momenti dell'attualità portano 1'enciclopedista, nell'ipotesi sostenuta, a rovesciare la tesi del $D e$ cive: «l'immagine di Medea, [...] condensa, com'è noto, i principi di un programma rivoluzionario, [e] fa dell'eloquenza politica lo strumento privilegiato per fare a pezzi il vecchio Esone (o la macchina incancrenita dell'ancien régime)» (p. 313).

3 Se è possibile ravvisare nel contributo di Goggi un certo utilizzo della congettura e dell'ipotesi, questo non va a demerito dell'autore che ha invece abilmente saputo, attraverso il proprio percorso tra documenti di necessità lacunosi e complessi (riprodotti nell'Appendice che segue), ricostruire il contesto storico d'un opera, l'Histoire des deux Indes, e individuarvi un Diderot dedito ad una rivalutazione dell'eloquenza, ciò che lo avvicina ai principi della politica repubblicana antica. 